Archives of Clinical and Medical Case Reports

doi: 10.26502 /acmcr.96550024

\title{
Obesity and Pregnancy in Saudi Women
}

\author{
Mohammad Othman ${ }^{1 *}$, Samah S Himayda ${ }^{2}$ and Lamia Shaaban ${ }^{3}$ \\ ${ }^{1}$ Department of Obstetrics and Gynecology, Faculty of Medicine, Al-Baha University, Saudi Arabia \\ ${ }^{2}$ Department of Obstetrics and Gynecology, Faculty of Medicine, Um Alqura University, Mecca, Saudi Arabia \\ ${ }^{3}$ Unit of Obstetrician and Gynecologist, Jeddah Maternity and Children Hospital, Jeddah, Saudi Arabia
}

*Corresponding Authors: Dr. Mohammad Othman, Department of Obstetrics and Gynecology, Faculty of Medicine, Al-Baha University, Saudi Arabia, E-mail: mothman12399@yahoo.com

Received: 26 February 2018; Accepted: 08 March 2018; Published: 15 March 2018

\section{Abstract}

Objective: To determine the effect of obesity on pregnancy compared to non-obese pregnant Saudi women.

Methodology: This is a prospective cohort research conducted over seven months in Jeddah Maternity and Children Hospital (MCH), Jeddah, Saudi Arabia. Sample included pregnant women with single fetus and cephalic presentation came to the booking clinic. Participants were classified into five groups depending on their BMI according to WHO criteria as underweight, normal weight, overweight, obese \& morbidly obese. SPSS was used with p-value of $<0.05$ to calculate statistical significance.

Results: The frequency of abortion, postdated pregnancy and Caesarean section were higher in obese women compared to non-obese women.

Conclusion: Obese women pregnancy is a high risk for pregnancy and labor complications. It is advisable to achieve normal BMI before conception.

Keywords: Obesity; Complications; Pregnancy

\section{Introduction}

The best parameter used to divide body weight is based on body mass index (BMI), defined as weight in kilograms divided by height in squared meters $\left(\mathrm{kg} / \mathrm{m}^{2}\right)$. The World Health Organization (WHO) divided BMI ranges into six categories to define different body weights from underweight, to obesity. Based on the 2011-2012 United States Health and Nutrition Examination Survey, there is $31.8 \%$ prevalence of obesity in 20-39 years old women and 
increases to $58.5 \%$ after combining overweight and obese groups [1, 2]. WHO BMI Categories are; Underweight (Less than 18.5), Normal weight (18.5-24.9), overweight (25.0-29.9), Obesity class I (30.0-34.9) Obesity class II (35.0-39.9), Obesity class III (40 or greater) [2].

Certain congenital anomalies risk increases in the offspring of obese women compared to non-obese women such as neural tube defects, hydrocephaly, cardiovascular, oro-facial, and limb reduction anomalies [3, 4]. Added to that, it was noticed that obese women compared with normal-weight women, are at increased risk of cardiac dysfunction, proteinuria, sleep apnea, nonalcoholic fatty liver disease [5], gestational diabetes mellitus [6], and preeclampsia [7]. Most importantly, risk of stillbirth is $40 \%$ in obese women than in non-obese women [8]. Obesity is an increasing problem in Saudi population, which can be explained in part by sedentary lifestyle, peculiar eating habits and diet rich in fat and carbohydrates [9]. A seldom number of studies carried out in Saudi Arabia to study prevalence of obesity and overweight in general population, and all concluded that obesity is high in both Saudi males and females [9-13].

Overweight mothers needs more prenatal and postnatal care since their infants require admission to neonatal intensive care units more often than do infants of normal-weight mothers. These infants are at higher risk for having congenital anomalies or being stillborn [14]. Added to that, cause-specific infant death is not well-recognized [15]. This study aimed to identify the effect of maternal obesity on pregnancy and its outcome.

\section{Methods}

This is a prospective cohort research conducted in Jeddah Maternity and Children Hospital (JMCH), Jeddah, Saudi Arabia. JMCH is a governmental tertiary hospital where medical care is given free of charge. JMCH cover most of region of Jeddah which is $281,990 \mathrm{~km}^{2}\left(78,680 \mathrm{mi}^{2}\right)$, with a total multi ethnic population of 3,977,933 [16]. JMCH number of deliveries is 5,500 per year on average, and caesarian section rate is $21 \%$. Because patients were be collected from the outpatient clinic, all patients came for antenatal care during January 2016 to July 2016 were recruited to join the study. Inclusion criteria include singleton pregnancy with cephalic presentation. While, exclusion criteria included multiple pregnancy, multiple CS and abnormal presentation. Outcome measures were frequency of BMI distribution, maternal complications of obesity and fetal complications of obesity.

The on duty nurse using standard techniques measured height and weight. Data were used to calculate BMI using the formula BMI= weight $(\mathrm{kg}) /$ height $(\mathrm{m})$. Depending upon BMI, the sample was divided into 5 groups; < 18.5 , 18.5-24.9, 25-29.9, 30-39.9 and $>40$ as underweight, normal weight, overweight, obese and morbidly obese respectively. Collection of data regarding complications during pregnancy and labor was recorded by the attending doctors on patient files. Files were reviewed at the end of pregnancy. Multiple logistic regression analysis was used

with SPSS Version 21 to evaluate the association between pregnancy BMI and pregnancy complications [17]. Data were adjusted for confounders to affect pregnancy outcomes. 


\section{Results}

Total numbers of women came for antenatal clinic was 1304, with 567 refused to join the research and 737 women joined. There was 21 cases under weight (2.8\%), 270 normal weight (36.6\%), 153 overweight (20.8\%), 207 obese (28.1\%), 86 morbidly obese (11.7\%) (Table 1$)$.

\begin{tabular}{|l|l|}
\hline Catogry & Frequency No (\%) \\
\hline Under weight & $21(2.8)$ \\
\hline Normal weight & $270(36.6)$ \\
\hline Over weight & $153(20.8)$ \\
\hline obese & $207(28.1)$ \\
\hline Morbidly obese & $86(11.7)$ \\
\hline Total & $737(100)$ \\
\hline
\end{tabular}

Table 1: Frequency of weight distribution in deferent groups.

Maternal complications according to categories (Table 2). Postdated pregnancy was more prominent in obese women and this was statistically significant. In addition, Gestational diabetes mellitus, pregnancy induced hypertension, preeclampsia and induction of labor was more frequent in obese women but did not reach to statistical significance. Abortion was more in obese women and statistically significant, while Postpartum heamorrage was more in obese women but not statistically significant.

\begin{tabular}{|l|l|l|l|l|l|l|}
\hline Complications & $\begin{array}{l}\text { Under } \\
\text { weight }\end{array}$ & $\begin{array}{l}\text { Normal } \\
\text { weight }\end{array}$ & $\begin{array}{l}\text { Over } \\
\text { weight }\end{array}$ & Obese & $\begin{array}{l}\text { Morbidly } \\
\text { Obese }\end{array}$ & P value \\
\hline Abortion & 6 & 4 & 18 & 57 & 21 & 0.03 \\
\hline GDM & 0 & 3 & 6 & 35 & 58 & 0.000 \\
\hline PET & 0 & 1 & 3 & 11 & 11 & 0.000 \\
\hline IOL & 0 & 15 & 9 & 66 & 11 & 0.000 \\
\hline PIH & 0 & 0 & 2 & 14 & 11 & 0.10 \\
\hline Post date & 0 & 28 & 31 & 141 & 12 & 0.01 \\
\hline PPH & 0 & 0 & 1 & 5 & 4 & 0.000 \\
\hline
\end{tabular}

Table 2: distribution of medical complications in different groups.

Mode of deliveries show more operative delivery in obese women which was statistically significant regarding cesarean section (Table 3). 


\begin{tabular}{|l|l|l|l|}
\hline Group & Cesarean & Ventouse & Vaginal delivery \\
\hline Under weight & 1 & 0 & 14 \\
\hline Normal weight & 16 & 1 & 249 \\
\hline Over weight & 15 & 2 & 118 \\
\hline obese & 64 & 7 & 79 \\
\hline Morbidly obese & 25 & 2 & 38 \\
\hline P value & 0.02 & 0.000 & 0.000 \\
\hline
\end{tabular}

Table 3: Mode of delivery in relation to obesity group.

There was eight cases of intrauterine fetal death (IUFD) (3.7\%) in the obese women but no other complications in any neonates in any group.

\section{Discussion}

The prevalence of obesity in our study found to be $39.8 \%$ that is almost the same prevalence reported in other studies. Obese women were at increased risk compared with the normal weight women to pregnancy induced hypertension, preeclampsia, gestational diabetes mellitus, induction of labor, operative vaginal delivery and postpartum haemorrhage, but this risk did not reach statistical significance. There is a significant increase in rate of abortion, postdate delivery and caesarian section in obese than normal weight women. This increase can be explained by increased deposition of fat in soft tissues of obese maternal pelvis, which will reduce the rate of cervical dilatation and may cause Cephalo-pelvic disproportion. This result is comparable to a study done by Sherrard [18].

We could not find a significant difference in the frequency of induction of labor between obese and normal weight woman, compared to other studies reporting a higher frequency. This could be due to the small number of participants in our study. Obesity is well known to be associated with macrosomia leading to potential adverse maternal outcomes from obstetric intervention (induction of labor, cesarean section and operative vaginal delivery) and adverse neonatal out comes from shoulder dystocia (birth injuries such as nerve palsies).

The study limited by the small number of participants, because it included only those women attending the outpatient clinic and agreed to participate. However, it adds to the increasing body of evidence suggesting that obesity measured by BMI predisposes women to increased risk of abortion, postdate delivery and caesarian section. Managing these problems and reducing their occurrence can pose a challenge to obstetrical care providers.

\section{Conclusion}

The results of our study indicate that obesity caries a significant increased risk for abortion, postdated pregnancy and caesarian delivery. Such patients should be advised for postpartum nutritional counseling, Preconception counseling, 
careful prenatal management, tight monitoring of weight gain, and long-term follow-up to minimize the social and economic consequences. Larger studies are needed in this area.

\section{Conflict of Interest}

None known

\section{References}

1. Ogden CL, Carroll MD, Kit BK, et al. Prevalence of childhood and adult obesity in the United States, 2011- 2012. JAMA 311 (2014): 806-814.

2. National Center for Health Statistics. NCHS obesity data. Hyattsville (MD): NCHS (2014).

3. Flegal KM, Carroll MD, Ogden CL, et al. Prevalence and trends in obesity among US adults, 1999-2008. JAMA 303 (2010): 235-241.

4. Stothard KJ, Tennant PW, Bell R, et al. Maternal overweight and obesity and the risk of congenital anomalies: a systematic review and meta-analysis. JAMA 301 (2009): 636-650.

5. Catalano PM. Management of obesity in pregnancy. Obstet Gynecol 109 (2007): 419-433.

6. Weiss JL, Malone FD, Emig D, et al. Obesity, obstetric complications and cesarean delivery rate--a population-based screening study. FASTER Research Consortium. Am J Obstet Gynecol 190 (2004):10911097.

7. Anderson NH, McCowan LM, Fyfe EM, et al. The impact of maternal body mass index on the phenotype of pre-eclampsia: a prospective cohort study. SCOPE Consortium. BJOG 119 (2012): 589-595.

8. Salihu HM, Dunlop AL, Hedayatzadeh M, et al. Extreme obesity and risk of stillbirth among black and white gravidas. Obstet Gynecol 110 (2007): 552-557.

9. Khashoggi RH, Madani KA, Ghaznawy HI. Socioeconomic factors affectingthe prevalence of obesity among femalepatients attending primary health centersin Jeddah, Saudi Arabia. Ecol Food Nutr 31 (1994): 277-283.

10. Al-Nuaim AR. Population based epidemiological study of the prevalence of overweight and obesity in Saudi Arabia, regional variation. Ann Saudi Med17 (1997): 195-199.

11. Rasheed P, Abou-Hozaifa BM, Khan A. Obesity among young Saudi female adults:a prevalence study on medical and nursingstudent. Public Health 108 (1994): 289-294.

12. Al-shammari SA, Khoja TA, Kremli M, et al. Low back pain and obesity inprimary health care, Riyadh, Saudi Arabia.Saudi Med J 15 (1994): 223-226.

13. Al-Nuaim HR, Al-Rubeaan KA, Al-Mazrou Y, et al. High prevalence of overweight and obesity in Saudi Arabia. Int J Obes Relat Meta Disord 20 (1996): 54752.

14. Morin KH, Reilly L. Caring for Obese Pregnant Women. JOGNN 36 (2007): 482-489.

15. Chen A, Feresu SA, Fernandez C, et al. Maternal Obesity and the Risk of Infant Death in the United States. Epidemiology 20 (2009): 74-81.

16. Information, C.D.O.S, Statistical Yearbook. Population. 47 (2011).

17. SPSS, IBM Corp. Released 2013. IBM SPSS Statistics for Windows, Version 21.0. Armonk, NY: IBM Corp. 
18. Sherrard A, Platt RW, Vallerand D, et al. Maternal anthropometric risk factors for caesarean delivery before or after onset of labor. BJOG 114 (2007): 1088-1096.

Citation: Mohammad Othman, Samah S Himayda, Lamia Shaaban. Obesity and Pregnancy in Saudi Women. Archives of Clinical and Medical Case Reports 2 (2018): 50-55.

(C) $\begin{aligned} & \text { This article is an open access article distributed under the terms and conditions of the } \\ & \text { Creative Commons Attribution (CC-BY) license } 4.0\end{aligned}$ 